\title{
Erratum to: Local Alendronic Acid Elution Increases Net Periimplant Bone Formation: A Micro-CT Analysis
}

\author{
J. Dennis Bobyn PhD, Rebecca Thompson MEng, Letitia Lim MD, \\ Jenny Ann Pura BSc, Kristian Bobyn BA, Michael Tanzer MD
}

Published online: 26 November 2013

(C) The Association of Bone and Joint Surgeons \& 2013

\section{Erratum to: Clin Orthop Relat Res DOI 10.1007/s11999-013-3120-6}

In the Materials and Methods section of the published study by Bobyn and colleagues, the abbreviation for HA is incorrectly defined. The corrected version should read: All implants were plasma spray-coated with a thin $(10-15 \mathrm{~lm})$ layer of hydroxyapatite (HA; 98\% purity, 99\% density, $64 \%$ crystallinity, calcium: phosphate ratio of 1.67) such that only the outermost porous structure was HA-coated, leaving the innermost pores uncoated.

The editors apologize for the error.

The online version of the original article can be found under doi:10.1007/s11999-013-3120-6.

J. D. Bobyn ( $\varangle)$, R. Thompson, L. Lim,

J. A. Pura, K. Bobyn, M. Tanzer

Jo Miller Orthopaedic Research Laboratory, Montreal General

Hospital, 1650 Cedar Avenue, Room LS1-409, Montreal,

QC H3G1A4, Canada

e-mail: john.bobyn@mcgill.ca

J. D. Bobyn, M. Tanzer

Division of Orthopaedic Surgery, Faculty of Medicine,

McGill University, Montreal, QC, Canada 